\title{
Engineering practices and engineering education: prolegomena to the model of the future
}

\author{
Nadezda Bagdasaryan ${ }^{1}$, Raisa Petruneva ${ }^{2, *}$,Valentina Vasilyeva $^{2}$, and Olga Toporkova ${ }^{2}$ \\ ${ }^{1}$ Bauman Moscow State Technical University, Baumanskaya 2-ya str., 5, 105005 Moscow, Russia \\ ${ }^{2}$ Volgograd State Technical University, Lenin Ave, 28, 400005 Volgograd, Russia
}

\begin{abstract}
A theoretical and methodological analysis of the content characteristics of engineering education correlated with the challenges of the fourth industrial revolution (Industry 4.0) showed that trends of the third technological revolution dominate in the current university engineers' training model. One of the effective tools for the formation of a university model for training an engineer of the future could be the ideas of using educational social engineering problems based on elements of sociohumanitarian expertise of engineering design decisions. An optimally designed model of an engineer of the future will improve the quality of training and, ultimately, avoid the negative (fatal) consequences of insufficiently substantiated engineering design decisions.
\end{abstract}

\section{Introduction}

In the near future, humanity will face a pivotal change in social and economic structures under the influence of accelerated technological development. The world is facing a change of such a magnitude and complexity humanity has never experienced before. It makes defining new vectors for the development of engineering activity and the corresponding engineering education topical taking into account objective features of modern technical, technological, and socio-economic life of society in Russia and the world, as well as the increased importance and critically fatal consequences of engineering practices. In specialized literature engineering practices are usually understood as a set of specific technical solutions. However, in our case this concept is expanded and included in the context of a technosphere as its structural element which includes the entire cycle of middle-level engineering activity: between the idea of a technical project and its social existence. This view and the corresponding methodology are caused by peculiarities of a new technological order in which engineering practices are associated with various systemic socio-cultural processes [1].

The design approach in engineering has led to a sharp expansion of the area of processes and phenomena that are difficult or almost impossible to diagnose in expressed measurements and calculations. These are processes associated with the impact on natural systems and phenomena, the transformation of engineering activities, infrastructural

\footnotetext{
${ }^{*}$ Corresponding author: raisa.petrunyova@yandex.ru
} 
changes in the society, and altogether with the impact of the result of engineering practices on society and the future of mankind. Engineering practices generate new types of material and spiritual needs of society, transform the axiological foundations of its life. Today there have been formed a situation that requires a change in the essence of engineering practice and professional attitudes of its carriers. When can this super task be implemented? What stage would be the best one? It is a well-known fact that motives, values, attitudes of professionals are formed in the learning process. This process requires serious changes, as well as a new ideology based on considering (forecasting) social and humanitarian consequences of implementation of engineering design decisions. The importance of fundamental development of the concept of training engineers for practical activity in the society of the future stems from the fact that a professional profile of such a specialist (model) must be considered as a set of parameters determined as by the current state of the industrial sector of economy, resource support of the training system, and other economic indicators, as personal characteristics of specialists which reflect their professional abilities and axiological priorities.

\section{Materials and Methods}

A number of works by Russian scientists are devoted to peculiarities of engineering design activities in a forecast manner [2-4]. There are a lot of works on transformation of higher engineering education (in the world practice and in Russia) and a new model of training engineers with the use of modern educational technologies [5-7]. An attempt to find out Western developments similar to our project did not detect complete analogs, i.e. complex studies of the evolution of models of an engineer in the context of various technological structures of the society. Meanwhile, there is a significant number of publications on individual components of the model abroad. The works [8-15] of foreign authors deserve particular attention.

We believe that it is methodologically reasonable to combine several sociophilosophical and pedagogical approaches.

The methodological basis of the project is a systems approach characterized by integrity, hierarchy, structuring, plurality and consistency (K.L. von Bertalanffy, I.V. Blauberg, A.A. Bogdanov, P. Drucker, B.F. Lomov, V.N. Sadovsky, G. Simon, A. Chandler, E. G. Yudin). This approach allows us to study each component of the system in an autonomous mode, analyze and compare them with each other, and then combine them into a holistic structure.

The subject-activity approach based on the scientific ideas of K.A. AbulkhanovaSlavskaya, A.V. Brushlinsky, L.S. Vygotsky, E.F. Zeer, A.N. Leontiev, S.L. Rubinstein, V.A. Slastenin, etc. provides an understanding of a subject as an actively acting personality possessing the function of self-activity in which he or she is both constructed and determined. The subject of this research project is an actively acting engineer who makes responsible professional decisions, and whose formation takes place in the professional educational environment in the unity of his or her psychological and pedagogical components.

The contextual approach is also important for solving the problem under study since it helps to strengthen the practical orientation of education at a higher school, implement the integration of theoretical and practical training of future engineers, and provide a natural connection between theoretical training and goals of future professional activities (A.A. Verbitsky, A.V. Raitsev, B.A. Takhohov, O.I. Fedotova, etc.).

The competence-based approach which we understand as an element of the methodological strategy of higher professional education focused on engineering practice in which key professional competencies ("hard skills") are combined with cross-cutting 
competencies ("soft skills") including social, communicative, environmental aspects of professional activity as well as self-organization skills (A.L. Andreev, V.I.Baydenko, R. Barnett, V.A. Bolotov, V. Vester, E.F. Zeer, I.A. Raven, L. Spencer, S. Spencer, G.K.Selevko, V.V.Serikov, A.V. Khutorskoy, G.A. Tsukerman, etc.).

Theoretical methods (comparative analysis of models of engineering activity and training, modeling of the corresponding processes, analysis of socio-philosophical, sociological and pedagogical literature, archival materials and documents; basic research concepts; identification of cause-and-effect relationships between the phenomena under study; forecasting) are used in order to solve the tasks put forward. Empirical methods (studying the process of training future engineers in modern conditions, collecting and accumulating data by observing, talks, questionnaires, tests, interviews, analysis of educational documentation and methodological activities products, teachers' work experience for subsequent analysis, etc.) are also applied.

The use of modern socio-philosophical and pedagogical approaches and methods to determine the essential characteristics of engineering activity, as well as the study of theory and practice of training future engineers allow us to determine the current context of the phenomenon under study.

\section{Results and discussion}

The challenges of rapid technological development followed by large socio-economic and cultural changes form relevant requirements for professional activity, and determine the construction of a new educational paradigm as a response. The strategic task of a new model of education systems is to create effective tools (drivers) for the long-term balanced evolution of civilization.

Modern social dynamics sets new requirements for a model of a specialist who is able not only to quickly, efficiently and flexibly engage in complex technological processes in order to create future technologies, and predict possible risks, but also solve global issues of climate change, natural disasters, population growth, urbanization, etc.

In a future-oriented model accents are changing in a range of knowledge, skills, abilities, and competencies that a modern higher school can provide. Today, as well as in the near future, there will be a demand for engineers oriented towards humanitarian values and related tools for professional engineering activities. They should have an outlook on the world that promotes the introduction of humanitarian values into the structure of meanings and goals of engineering practices. They will be good not only at a narrow, specialized field, but also able to go beyond the scope of their professional subject, and make a breakthrough in related areas. They will be able to fit into the context of the modern era and see their place in the global system of social and economic communications, understand and anticipate the trends in the development of a technosphere and related institutions.

According to the experts [10-12], a new list of knowledge and skills has already been formed in the public mind which sets unique models for training of future specialists, but the education system does not quite successfully cope with training of such professionals. The shortage of specialists capable of solving creative tasks in a dynamic society characterized by such features as complexity, openness, nonlinearity, uncertainty, selforganization is obvious [13]. The main feature of modern engineering activity is that it unites and reflects fundamental problems of the relationship between material and spiritual production, technical, technological and scientific progress, science and education, the technosphere, the biosphere and the sociosphere. Modern engineering problems cannot be solved outside the socio-technical approach, their solution involves two components: rational-gnostic (technical solution) and axiological (humanitarian solution). The 
professionalism of an engineer of the future is determined by his or her ability to treat a technical problem as an integral socio-cultural problem.

The structural element of professional training of engineers is a cycle of social and humanitarian disciplines, its significance being actualized by modern trends in social dynamics: numerous global challenges create the basis (as well as demand) for an interdisciplinary, integrative solution of complex problems. Modern engineering tasks by their nature are objects of a complex socio-technical nature, therefore the inherent qualities of design objects often oppose engineering design influences and require a range of qualities from an engineer, which should be formed in the process of higher education.

Any state wants to have a system of education that would be in congruence with its geopolitical and economic interests. According to many tertiary educators, any restructuring in this system takes five to ten years.

The decline in economic activity in almost all countries of the world caused by the COVID-19 pandemic was the main reason for the decline in the labor market demand for engineers. The recovery from the crisis and economic revival raise the question of what kind of engineers our aspiring for the future society will need. What competences should they posses? It must be taken into account that the future will never be the same we are accustomed to. Thus, the problem of developing a prognostic model of an engineer as a creator of new material needs of the future society in the new realities of human existence is becoming more urgent than ever, as well as a model for training such engineers at a higher technical school.

To understand what an engineer of the future should be like, and how prepare him, it is first necessary to make a forecast of the socio-cultural, technical, and technological situation in the near future. The educational process design at a technical university in accordance with the prognostic model of an engineer has great potential for professional and personal development of engineers of the future and it is one of the tools for improving the quality of human capital. The long-term result will guarantee the preservation of a highquality human habitat in the dynamics of technological revolutions.

The systematization of scientific ideas of Russian and foreign researchers about the genesis of "model of an engineer" concept in various technological structures of social production showed the essential characteristics of this phenomenon, made it possible to determine its structural and content components, and develop theoretical and methodological foundations for its design. The identified structure, dynamics (mechanisms), and factors of the influence of engineering practices on transformation of society's life make it possible to develop methods for their integration with the structure and dynamics of training future engineers in the system of higher technical education.

The progressive experience of the world's leading universities of engineering education demonstrates the need to build the educational process of the university on the basis of the prognostic model of an engineer. The possibility of designing such a model appears when a complex of methodological approaches is used, while "white spots" and "points of growth" in the practice of Russian engineering personnel training system are identified. The key task is to combine the competencies acquired at a university, requirements of engineering practices and the socio-cultural assessment of the forecast of their impact (both short-term and long-term) on the life of society.

The novelty of the project lies in the fact that for the first time engineering education is presented as a holistic concept based on the analysis of engineering activity characteristics in the context of the fourth industrial revolution which has enhanced the role and responsibility of an engineer as a creator of new material needs of the future society in new realities of human existence. Engineering activity like any other activity has a social nature. At the same time, it is connected with transformation of the natural into the artificial. Its 
core is engineering design since the work of an engineer has a technical content closely related to science which turns into a direct productive force [14].

The main components of the concept are target and essential characteristics of engineering activity presented in the form of a structural and functional model, the corresponding methods of constructing the content (technology) of engineering training based on a new ideology, the core of which is the forecast of social and humanitarian consequences of engineering and design solutions implementation. The difference between this project and others lies in the holistic presentation of engineering training at a technical university in relation to the current state of a technical and technological sphere of society, engineering practices, and their impact on the life of society.

\section{Conclusion}

The results of this research have theoretical and practical significance and can be used by specialists in the design of engineering training system transformations. Theoretical provisions and conclusions provide additional opportunities for further expansion of theoretical and methodological research on the problem of engineering practices and engineering education. The materials obtained can also be used in the development and adjustment of educational programs aimed at the formation and development of "competence of the future" in accordance with the proposed prognostic model of an engineer. In addition, the research materials can be used as the basis for design and development of training courses, special courses and seminars in social and humanitarian disciplines.

\section{References}

1. N.G. Bagdasaryan. Philosophy and Sociology of technology in the XXI century, 78 (2018)

2. Yu.P. Pokholkov, Engineering Education, 10, 50 (2012)

3. A.I. Chuchalin, Higher Education in Russia, 10, 47 (2018)

4. R.M. Petruneva, V.D. Vasilyeva, MEJSR, 18(2), 210 (2013)

5. V.N. Zuev. Designing a theoretical model of training an engineer for environmentally friendly production activities, http://rep.barsu.by/

6. N.V. Molotkova, M.A. Sviryaeva. Competence model of a modern engineer as the basis for the design of an educational program, http://vernadsky.tstu.ru/

7. C. Mitcham, A.A. Kazakova, Philosophy of Science and Technology, 25(2), 26 (2020)

8. B. Motyl. Procedia Manuf, 11, 1501 (2017)

9. E. Subrahmanian, T. Odumosu, J. Tsao, Engineering a Better Future: Interplay Between Engineering, Social Sciences, and Innovation. Springer Nature (2018)

10. A. Korshunov, Science and Innovation, 2, 18 (2019)

11. N.K. Okonskaya, T.D. Sterledeva, Bulletin of the PNRPU, Culture, History, Philosophy, Law, 2, 48 (2015)

12. R.I. Sharafutdinova, I.I. Galimzyanova, Bulletin of the Kazan Technological University, 6, 255 (2012)

13. N.V. Popkova, Philosophy of Science and Technology, 23(2), 49 (2018)

14. Engineer-philosophy-University (1990) 